\title{
Effect of co-ingestion of amino acids with rice on glycaemic and insulinaemic response
}

\author{
Yean Yean Soong ${ }^{1}$, Joseph Lim ${ }^{1}$, Lijuan Sun ${ }^{1}$ and Christiani Jeyakumar Henry ${ }^{1,2,3 *}$ \\ ${ }^{1}$ Clinical Nutrition Research Centre, Singapore Institute for Clinical Sciences, Singapore 117599, Singapore \\ ${ }^{2}$ Singapore Institute for Clinical Sciences, Agency for Science, Technology and Research (A*STAR), Singapore 117609, \\ Singapore \\ ${ }^{3}$ Department of Biochemistry, National University of Singapore, Singapore 117596, Singapore
}

(Submitted 29 July 2015 - Final revision received 3 August 2015 - Accepted 18 August 2015 - First published online 30 September 2015)

\section{Abstract}

Consumption of high glycaemic index (GI) and glycaemic response (GR) food such as white rice has been implicated in the development of type 2 diabetes. Previous studies have reported the ability of individual amino acids to reduce GR of carbohydrate-rich foods. Because of the bitter flavour of amino acids, they have rarely been used to reduce GR. We now report the use of a palatable, preformed amino acid mixture in the form of essence of chicken. In all, sixteen healthy male Chinese were served 68 or $136 \mathrm{ml}$ amino acid mixture together with rice, or 15 or 30 min before consumption of white rice. Postprandial blood glucose and plasma insulin concentrations were measured at fasting and every 15 min after consumption of the meal until $60 \mathrm{~min}$ after the consumption of the white rice. Subsequent blood samples were taken at 30-min intervals until $210 \mathrm{~min}$. The co-ingestion of $68 \mathrm{ml}$ of amino acid mixture with white rice produced the best results in reducing the peak blood glucose and GR of white rice without increasing the insulinaemic response. It is postulated that amino acid mixtures prime $\beta$-cell insulin secretion and peripheral tissue uptake of glucose. The use of ready-to-drink amino acid mixtures may be a useful strategy for lowering the high-GI rice diets consumed in Asia.

Key words: Amino acid mixtures: Essence of chicken: White rice: Glycaemic response: Insulin response

Asia remains the global epicentre for type 2 diabetes (T2D). A recent survey indicated that in China, India and South East Asia alone there are approximately 250 million people diagnosed with $\mathrm{T} 2 \mathrm{D}^{(1)}$. It has been proposed that for every diagnosed diabetic there exists three to five undiagnosed diabetics ${ }^{(1)}$. The conventional strategy for the management of T2D remains the use of drugs and insulin ${ }^{(2-5)}$. An emerging trend has been the identification of food and food ingredients to modulate glucose response; food has now become the new medicine ${ }^{(6-10)}$. Over a century ago, Lusk reported a close link between protein intake and glucose metabolism ${ }^{(11,12)}$. Subsequently, a series of studies pioneered by Gannon \& Nuttall ${ }^{(11)}$ reported the effects of individual amino acids on glucose homoeostasis. In their earlier studies, these authors reported marked increases in insulin response and glycaemic control to individual amino acids; for example, isoleucine (Ile) and phenylalanine (Phe) were the two amino acids that had the greatest effect $^{(11,13)}$. Since these early observations, several researchers have attempted to develop a cocktail of amino acids that will facilitate glycaemic control ${ }^{(14-17)}$. However, because of the bitter taste of free amino acids, their application has remained a scientific curiosity ${ }^{(18,19)}$. Indeed, it has not been exploited as a dietary component for managing glucose homeostasis. We now report the use of a preformed amino acid that is readily available in the form of essence of chicken (EOC) to reduce the glycaemic response (GR) of rice.

The amino acid mixture in EOC is produced by subjecting chicken meat to cooking for several hours under high temperature and high pressure. The resulting water extract is concentrated and bottled. The solid content consists mainly of low-molecular-weight proteins, peptides and amino acids.

The amino acid mixture in the form of EOC is presented in Table 1 , along with its variability.

The EOC has been used as a therapeutic food in much of Asia for over a century ${ }^{(13,20,21)}$. The special flavour of amino acid mixtures is acceptable by many people living in Asia. The consumption of amino acid mixtures is believed to promote postpartum lactation in females and enhance immunity in humans ${ }^{(21)}$. EOC has also been demonstrated to exert a series of physiological responses, including improvement in immunity

Abbreviations: EOC, essence of chicken; GI, glycaemic index; GR, glycaemic response; IAUC, incremental AUC; IGI, insulinogenic index; IR, insulinaemic response; T2D, type 2 diabetes.

* Corresponding author: C. J. Henry, fax +65 6776 6840, email jeya_henry@sics.a-star.edu.sg 
Table 1. Amino acid profile of essence of chicken determined by HPLC $(n 3)^{*}$

\begin{tabular}{lcc}
\hline Amino acids and peptide $\dagger$ & Concentration $(\mathrm{mg} / 100 \mathrm{~g})$ & $\mathrm{SD}$ \\
\hline Asp & 486 & $2 \cdot 08$ \\
Thr & 196 & $2 \cdot 08$ \\
Ser & 205 & 0.00 \\
Gln & 917 & $2 \cdot 08$ \\
Pro & 473 & 13.7 \\
Gly & 773 & $5 \cdot 86$ \\
Ala & 493 & 3.51 \\
Val & 210 & $2 \cdot 65$ \\
Ile & 169 & $1 \cdot 53$ \\
Leu & 338 & 0.58 \\
Tyr & 102 & 0.00 \\
Phe & 156 & 0.58 \\
Lys & 378 & $9 \cdot 29$ \\
His & 169 & $2 \cdot 08$ \\
Arg & 581 & 3.61 \\
Cys & 14.5 & 0.81 \\
Met & 119 & $2 \cdot 08$ \\
Trp & $22 \cdot 8$ & 0.67 \\
Carnosine† & 80 & NA \\
\hline
\end{tabular}

* Covance (Asia) Pte Ltd

$\dagger$ Results adapted from Li et al. ${ }^{(21)}$

and relief from stress ${ }^{(13,21)}$. EOC has also been shown to increase glucose tolerance and insulin sensitivity in rats ${ }^{(22)}$. However, its role in GR and insulinaemic response (IR) has never been studied or tested in humans.

The co-ingestion of protein with carbohydrate, such as potato, white bread or glucose solutions, to reduce the GR has been widely researched ${ }^{(11,23,24)}$. White rice is the major staple diet in most regions of Asia. White rice is also classified as a high glycaemic index (GI) food. GI may be described as the ability for a defined portion of carbohydrate $(50 \mathrm{~g})$ to raise blood glucose over a period of $120 \mathrm{~min}^{(25)}$. The increased consumption of high-GI food has been implicated in the escalating prevalence of $\mathrm{T} 2 \mathrm{D}$ in $\mathrm{Asia}^{(26,27)}$. Interest has recently focused on incorporating food and food ingredients to reduce the GR of high-carbohydrate-rich food ${ }^{(10,28,29)}$. This study aims to explore the effects of an amino acid mixture on GR and IR when ingested with white rice. The dose and time-course effects of amino acid mixtures were examined in order to determine its optimal effect on GR and IR.

\section{Methods}

\section{Subjects}

The study was conducted at the Clinical Nutrition Research Centre, A*Star, Singapore. In all, sixteen healthy Chinese male participants with a BMI between 18 and $24.9 \mathrm{~kg} / \mathrm{m}^{2}$, aged $21-50$ years, with blood pressure $<120 / 80 \mathrm{mmHg}$ and fasting blood glucose $<6 \mathrm{mmol} / \mathrm{l}$, were recruited. Physical activity levels were quantified using the questionnaire of Baecke et al. ${ }^{(30)}$. Those partaking in competitive sports and endurance events were excluded. A food acceptance questionnaire was used to evaluate the preference for consuming amino acid mixtures. Only those who preferred the taste of EOC were included. Smokers, subjects with genetic or metabolic diseases and those on prescribed medication were excluded. The study was conducted
Table 2. Dose and time of amino acid delivered in each treatment

\begin{tabular}{lcc}
\hline Treatment numbers & $\begin{array}{c}\text { Amino acid } \\
\text { mixture }(\mathrm{ml})\end{array}$ & $\begin{array}{c}\text { Time before consumption } \\
\text { of white rice }(\mathrm{min})\end{array}$ \\
\hline T1 & 0 & 0 \\
T2 & 63 & 0 \\
T3 & 63 & 15 \\
T4 & 63 & 30 \\
T5 & 136 & 0 \\
T6 & 136 & 15 \\
T7 & 136 & 30 \\
\hline
\end{tabular}

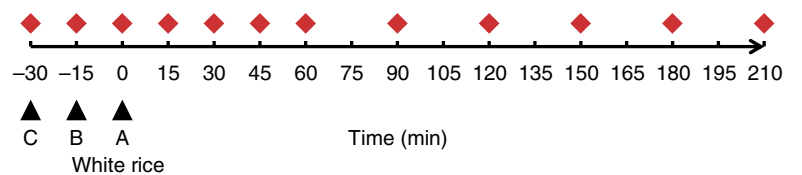

Fig. 1. Protocol and schedule for treatment meal and blood sampling. A: $68 \mathrm{ml}$ (T2) or $136 \mathrm{ml}$ (T5); B: $68 \mathrm{ml}$ (T3), $136 \mathrm{ml}$ (T6); C: $68 \mathrm{ml}$ (T4), $136 \mathrm{ml}$ (T7). $\mathbf{\Delta}$, Ingestion of treatment meal; $>$, blood sampling time point.

according to the ethical guidelines laid down by the Declaration of Helsinki and initiated after formal approval by the Domain Specific Review Board (DSRB) of the National Healthcare Group. This study was registered with the DSRB, Singapore, under registration number 2014/00366. All subjects gave informed, written consent. The subjects were asked to restrict their intake of alcohol and caffeine-containing drinks, as well as to avoid intense physical activity on the evening preceding the test day.

\section{Study protocol}

The subjects visited our laboratory on seven separate occasions. They received in random order the following food mixtures: (T1) white rice alone; (T2) white rice plus $68 \mathrm{ml}$ of amino acid mixture; (T3) $68 \mathrm{ml}$ of amino acid mixture $15 \mathrm{~min}$ before rice consumption; (T4) $68 \mathrm{ml}$ of amino acid mixture $30 \mathrm{~min}$ before rice consumption; (T5) white rice plus $136 \mathrm{ml}$ of amino acid mixture; (T6) $136 \mathrm{ml}$ of amino acid mixture $15 \mathrm{~min}$ before rice consumption; and (T7) $136 \mathrm{ml}$ of amino acid mixture $30 \mathrm{~min}$ before white rice consumption. Table 2 and Fig. 1 present a schematic illustration of the protocol.

White rice (FairPrice Golden Royal dragon Thai Hom Mali rice) was purchased from NTUC FairPrice and the amino acid mixture was obtained from Cerebos. After receiving the treatment, blood samples were taken every $15 \mathrm{~min}$ for the 1 st hour after consumption of white rice and then every $30 \mathrm{~min}$ until $210 \mathrm{~min}$ after consumption of rice. The procedure and protocol are described in Fig. 1.

Participants were encouraged to keep their physical activity to a minimum on the morning before the test. During the testing session, they were discouraged from walking briskly and were instructed to stay calm and seated. Access to a computer, a reading area and television facilities were provided. Upon completion of the seven sessions, the participants were debriefed and compensated for their time and transportation cost. 


\section{Blood analysis}

Blood glucose was measured by following the method described by Brouns et $a l .{ }^{(31)}$. Participants were encouraged to warm their hand before a finger-prick to increase blood flow. Blood was expressed by massaging the finger gently from the base toward the tip to minimise plasma dilution. An aliquot of $5 \mu \mathrm{l}$ blood sample was collected using an Abbott $\mathrm{SF}^{\circledR}$ single-use lancing device (Owen Mumford). Capillary blood glucose was measured using calibrated HemoCue Glucose 201+ analysers (HemoCue ${ }^{\circledR}$ Ltd). The capillary blood samples $(300 \mu \mathrm{l})$ were collected into $\mathrm{K}_{2}$ EDTA tubes (Becton, Dickinson and Company) for insulin analysis. Blood samples were stored on ice and the plasma was separated by centrifugation (10 min, $1000 \mathrm{~g}, 4^{\circ} \mathrm{C}$ ) (Sorvall $^{\mathrm{TM}}$ ST 16 Centrifuge; Thermo Fisher Scientific Inc.). The plasma was stored in microcentrifuge tubes at $-80^{\circ} \mathrm{C}$ for future analysis. Plasma insulin was determined on the immunoassay analyzer Cobas e 411 (Roche Diagnostics $\mathrm{GmbH})^{(32,33)}$.

\section{Statistics}

GR and IR data were converted to 'the change in GR' and 'the change in IR' values. These values were calculated by computing the difference between the blood glucose and plasma insulin concentration at a time point $(-30,-15,0,15,30,45,90$, 120, 150, 180 and $210 \mathrm{~min}$ ) from the mean baseline blood glucose and plasma insulin concentrations (at $0 \mathrm{~min}$ ), respectively. The change in GR and IR represented the relative increment in the GR and IR at any time point compared with baseline values. They were used for all further analyses including blood glucose response and plasma insulin response curve construction, incremental AUC (IAUC) calculation, as well as for statistical analysis. The total postprandial blood glucose and plasma insulin responses were expressed as IAUC ignoring the area beneath the baseline. Both IAUC were calculated geometrically using the trapezoidal rule (31,34) $^{\text {. }}$

Insulinogenic index (IGI), the ratio of the incremental insulin concentration to the incremental glucose concentration in the 30 min sample, was used to assess the $\beta$-cell function ${ }^{(35-37)}$ :

IGI was computed as follows:

$$
\Delta \mathrm{I}_{30} / \Delta \mathrm{G}_{0}\left(\mathrm{I}_{30}-\mathrm{I}_{0}\right) /\left(\mathrm{G}_{30}-\mathrm{G}_{0}\right) .
$$

Statistical analysis was conducted using the Statistical Package for the Social Sciences version 16 (SPSS Inc.). Data and figures were processed in a Microsoft Excel spreadsheet (Microsoft Corporation). The glucose and insulin AUC, the incremental change in GR and IR, preprandial glucose and insulin concentration, incremental peak glucose and insulin concentration, the difference between peak and nadir concentration of glucose and insulin, as well as IGI values were subjected to repeated-measures ANOVA. After demonstrating significant heterogeneity, the least significant differences between individual means were obtained by pairwise comparisons. The criterion for significance was a two-tailed $P$ value $<0 \cdot 05$. Pearson's correlation analysis was used to compare the association between IGI and glucose IAUC at $120 \mathrm{~min}$.

\section{Results}

\section{Baseline characteristics of subjects}

The baseline characteristics of the subjects are given in Table 3, and the anthropometric data were within the normal ranges for this population.

\section{Peak blood glucose levels}

Consumption of the amino acid mixture with rice reduced the blood glucose level compared with consumption of white rice alone. However, as indicated in Table 4, only co-ingestion of $68 \mathrm{ml}$ of amino acid mixture with rice reached statistical significance $(P<0 \cdot 05)$

\section{Glycaemic response}

The co-ingestion of 68 or $136 \mathrm{ml}$ of amino acid mixture with white rice resulted in a dramatic decline in blood glucose levels. The total IAUC for both 68 and $136 \mathrm{ml}$ of amino acid mixture was significantly lower than that for white rice $(P<0.05)$; however, there was no difference between the consumption of either 68 or $136 \mathrm{ml}$ of amino acid mixture (Fig. 2(a) and (b)).

When considering the time effects of amino acid mixtures, it was evident that feeding 68 or $136 \mathrm{ml}$ of amino acid mixture $15 \mathrm{~min}$ before ingestion of white rice reduces the glucose response $(P<0 \cdot 05)$. However, there was no difference between 68 and $136 \mathrm{ml}$ of amino acid mixture consumed $15 \mathrm{~min}$ before the consumption of rice. Finally, it was only the ingestion of

Table 3. The baseline characteristics of subjects were age, height (ht), weight (wt), BMI, waist circumference (WC) and fasting blood glucose (FBG) (Averages with their standard deviations)

\begin{tabular}{lcccccc}
\hline & $\begin{array}{c}\text { Age } \\
(\text { years })\end{array}$ & $\begin{array}{c}\mathrm{Ht} \\
(\mathrm{m})\end{array}$ & $\begin{array}{c}\text { Wt } \\
(\mathrm{kg})\end{array}$ & $\begin{array}{c}\text { BMl } \\
\left(\mathrm{kg} / \mathrm{m}^{2}\right)\end{array}$ & $\begin{array}{c}\text { WC } \\
(\mathrm{cm})\end{array}$ & $\begin{array}{c}\text { FBG } \\
(\mathrm{mmol} / \mathrm{l})\end{array}$ \\
\hline Average & 24.7 & 1.72 & 63.6 & 21.5 & 75.4 & 4.61 \\
SD & 3.93 & 0.04 & 4.84 & 1.50 & 5.10 & 0.43 \\
\hline
\end{tabular}

Table 4. Peak time and glucose concentration (Mean values with their standard errors)

\begin{tabular}{lllc}
\hline & \multicolumn{3}{c}{ Peak glucose } \\
\cline { 2 - 4 } & & \multicolumn{2}{c}{ Concentration $(\mathrm{mmol} / \mathrm{l})$} \\
\cline { 2 - 4 } Treatments & Time (min) & Mean & SE \\
\hline T1 & 45 & $2 \cdot 79^{\mathrm{a}}$ & 0.25 \\
T2 & 30 & $2 \cdot 23^{\mathrm{b}}$ & 0.11 \\
T3 & 30 & $2 \cdot 02$ & 0.23 \\
T4 & 30 & $2 \cdot 61$ & 0.15 \\
T5 & 30 & $2 \cdot 28$ & 0.22 \\
T6 & 30 & $2 \cdot 13$ & 0.16 \\
T7 & 45 & $2 \cdot 19$ & 0.29 \\
\hline
\end{tabular}

(T1) white rice; white rice with amino acids (T2) $68 \mathrm{ml}$ at $0 \mathrm{~min}$, (T3) $68 \mathrm{ml}$ at $-15 \mathrm{~min}$, (T4) $68 \mathrm{ml}$ at $-30 \mathrm{~min}$, (T5) $136 \mathrm{ml}$ at $0 \mathrm{~min}$, (T6) $136 \mathrm{ml}$ at $-15 \mathrm{~min}$ and (T7) $136 \mathrm{ml}$ at $-30 \mathrm{~min}$.

a,b Mean values within a column with unlike superscript letters were significantly different $(P<0.05)$. 
(A)

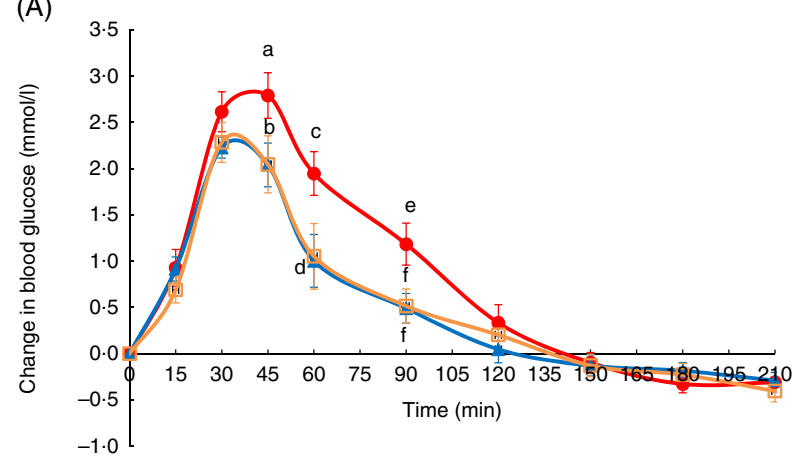

(B)

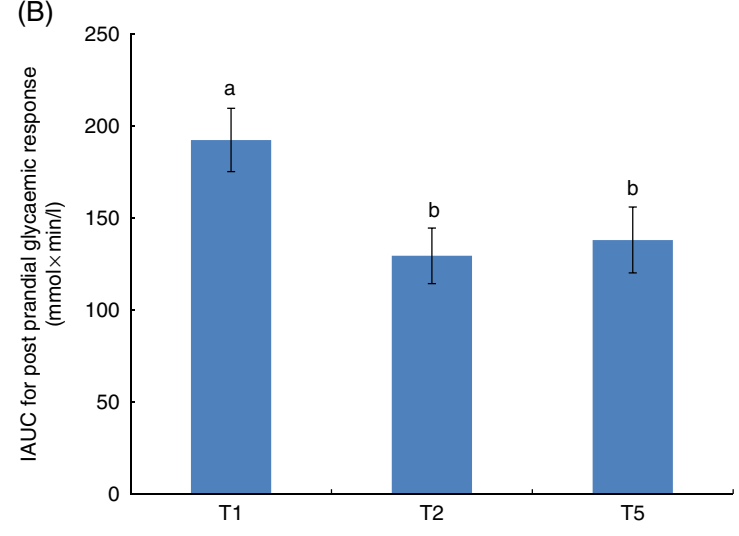

Fig. 2. (A) Mean changes in capillary blood glucose and (B) incremental AUC (IAUC) glucose in healthy subjects $(n 16)$ after consumption of the test meals.

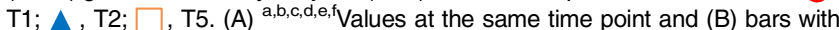
unlike letters were significantly different $(P<0.05)$. (T1) White rice; white rice with amino acids (T2) $68 \mathrm{ml}$ at $0 \mathrm{~min}$, (T3) $68 \mathrm{ml}$ at $-15 \mathrm{~min}$, (T4) $68 \mathrm{ml}$ at $-30 \mathrm{~min}$, (T5) $136 \mathrm{ml}$ at $0 \mathrm{~min}$, (T6) $136 \mathrm{ml}$ at $-15 \mathrm{~min}$ and (T7) $136 \mathrm{ml}$ at $-30 \mathrm{~min}$.

$136 \mathrm{ml}$ of amino acid mixture at $30 \mathrm{~min}$ before consumption of white rice that produced a reduction in GR.

\section{Insulinaemic response}

There were no differences in IR between co-ingestion of $68 \mathrm{ml}$ and that of $136 \mathrm{ml}$ amino acid mixture with white rice when compared with consumption of white rice alone (Fig. 3(a) and (b)). When considering the time effects, 15 min before consumption of white rice, only $68 \mathrm{ml}$ of amino acid mixture demonstrated a reduction in IR compared with white rice alone $(P<0.05)$. At time $30 \mathrm{~min}$ (T4 and T7), only the consumption of $136 \mathrm{ml}$ of amino acid mixture demonstrated a reduction in IR (T7) $(P<0 \cdot 05)$.

\section{Insulinogenic index}

The IGI at $30 \mathrm{~min}$ measures the ratio of insulin increment to glucose increment shortly after a meal at $30 \mathrm{~min}^{(35-37)}$. The IGI had been validated against the hyperinsulinaemic-euglycaemic clamp and intravenous glucose tolerance studies for measurement of $\beta$-cell function and insulin sensitivity in normal glucosetolerant and prediabetic subjects ${ }^{(35-37)}$. The changes in IGI were correlated to the changes in the $\beta$-cell function in both normal glucose-tolerant and prediabetic individuals, which suggests it to be a valid proxy indicator for $\beta$-cell function in healthy individuals ${ }^{(35)}$. In case-controlled studies on prediabetics and
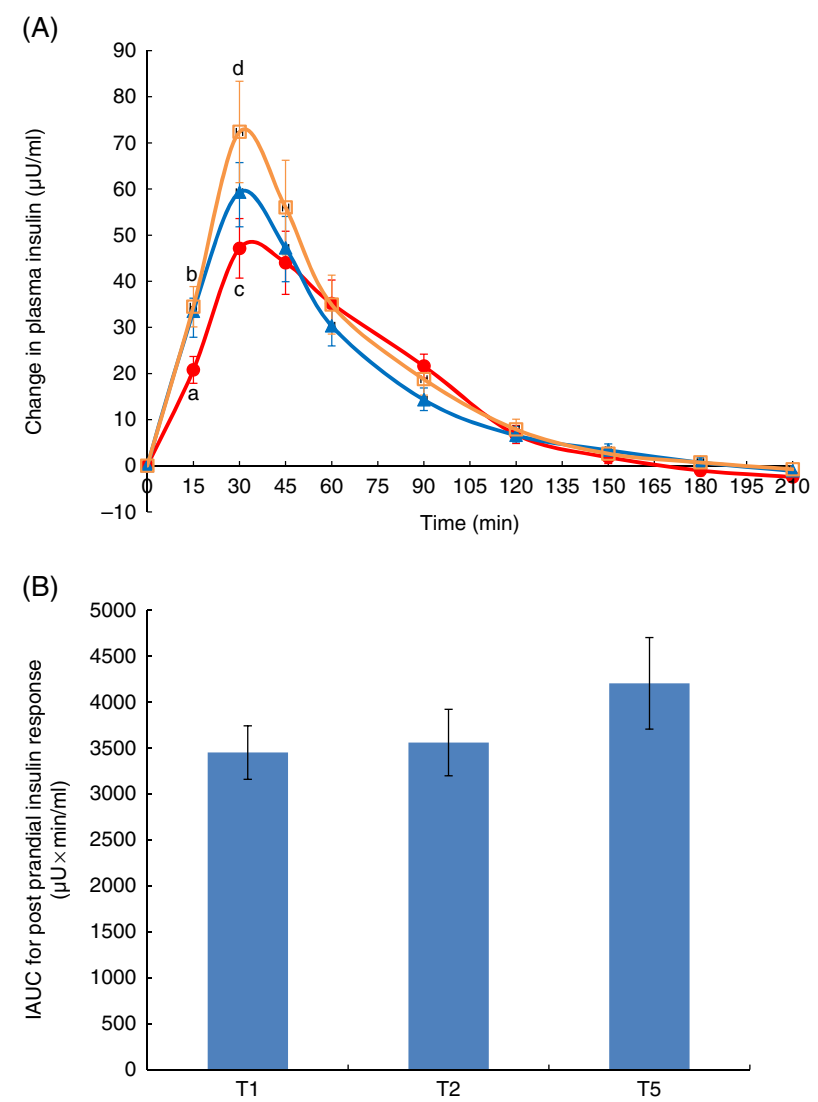

Fig. 3. (A) Mean changes in plasma insulin and (B) incremental AUC (IAUC) insulin in healthy subjects $(n 16)$ after consumption of the test meals. T1; $\Delta, \mathrm{T} 2 ; \square, \mathrm{T} 5$. (A) ${ }^{\mathrm{a}, \mathrm{b}, \mathrm{c}, \mathrm{d}}$ Values at the same time point with unlike letters were significantly different $(P<0.05)$. (T1) White rice; white rice with amino acids (T2) $68 \mathrm{ml}$ at $0 \mathrm{~min}$, (T3) $68 \mathrm{ml}$ at $-15 \mathrm{~min}$, (T4) $68 \mathrm{ml}$ at $-30 \mathrm{~min}$, (T5) $136 \mathrm{ml}$ at $0 \mathrm{~min}$, (T6) $136 \mathrm{ml}$ at $-15 \mathrm{~min}$ and (T7) $136 \mathrm{ml}$ at $-30 \mathrm{~min}$.

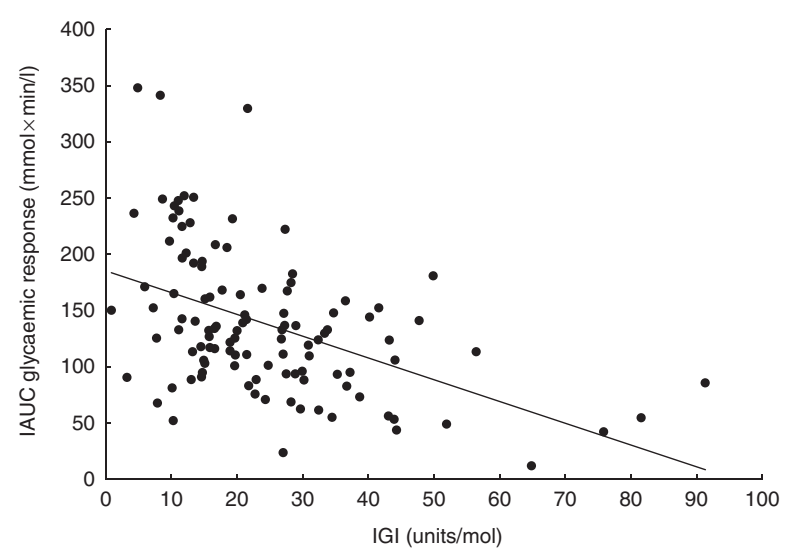

Fig. 4. Incremental AUC (IAUC) glycaemic response at $120 \mathrm{~min} v$. insulinogenic index (IGI). $R^{2} 0.22(P<0.01)$.

diabetics, it was observed that such groups had reduced IGI compared with normal glucose-tolerant subjects ${ }^{(35-37)}$.

When the results from all IGI and GR were pooled from the seven treatments, a statistical association was observed between IGI and IAUC at 120 and $210 \mathrm{~min}(P<0 \cdot 01)$. Increased IGI was 
found to be negatively correlated with the IUAC of blood glucose at 120 min (Pearson's correlation $r-0 \cdot 47 ; P<0 \cdot 01$ ) (Fig. 4). This suggests that the mechanism of action of EOC on GR was mediated by the ability of the amino acid mixture to influence insulin secretion.

\section{Discussion}

The present study is the first to report a dose-response and time-course effect of amino acid mixtures on its ability to lower the GR of white rice in healthy Chinese males.

The GR can broadly be influenced by (a) the amount of glucose absorbed into the circulatory system and (b) the amount of glucose removed from the circulatory system within a finite period of time ${ }^{(25,31)}$. Some of the major strategies to lower GR are retardation of glucose absorption, inhibition of carbohydrate digestion, reduction of gastric-transit time and use of ingredients to provide a physical barrier to the absorption of carbohydrates $^{(25,31)}$. In contrast, ways to increase glucose clearance include the stimulation of insulin secretion to facilitate glucose uptake. In this study, no increase in insulin secretion was observed $^{(25,31)}$. It is therefore likely that amino acids reduce GR through increased insulin sensitivity or delayed gastric emptying. This speculation needs to be further investigated.

Ingestion of an amino acid mixture increases the IGI compared with white rice alone (Table 5). However, the effect was only statistically significant when the amino acid mixture was co-ingested with white rice $(P<0 \cdot 05)$, regardless of whether 68 or $136 \mathrm{ml}$ of amino acid mixture was used. There was no significant effect on IGI when the amino acid mixture was consumed either 15 or $30 \mathrm{~min}$ before consumption of rice. The IGI finding (Table 5) shows that the insulin response at $30 \mathrm{~min}$ coincides with the lower peak glucose concentration (Table 4). Drugs have been widely used to control rapid excursion and decline in glucose in T2D to prevent disease complications ${ }^{(38,39)}$. Our observation that food-based amino acid mixtures could

Table 5. Peak insulin time and concentration, difference between incremental peak and nadir insulinaemic response, and insulinogenic index (IGI) of the plasma insulin in healthy subjects

(Mean values with their standard errors)

\begin{tabular}{|c|c|c|c|c|c|c|c|}
\hline \multirow[b]{3}{*}{ Treatments } & \multicolumn{3}{|c|}{ Incremental peak insulin } & \multirow{2}{*}{\multicolumn{2}{|c|}{ 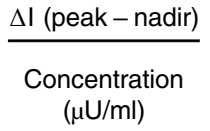 }} & \multicolumn{2}{|c|}{$\mid \mathrm{GI}$} \\
\hline & \multirow[b]{2}{*}{ Time (min) } & \multicolumn{2}{|c|}{$\begin{array}{c}\text { Concentration } \\
(\mu \mathrm{U} / \mathrm{ml})\end{array}$} & & & \multicolumn{2}{|c|}{$(\mathrm{U} / \mathrm{mol})$} \\
\hline & & Mean & SE & Mean & SE & Mean & SE \\
\hline $\mathrm{T} 1$ & 30 & $47 \cdot 2^{a}$ & 6.44 & $49 \cdot 6^{c}$ & $6 \cdot 68$ & $18 \cdot 2^{\mathrm{e}}$ & 2.18 \\
\hline $\mathrm{T} 2$ & 30 & $59 \cdot 3$ & $7 \cdot 48$ & $60 \cdot 4$ & $8 \cdot 81$ & $27 \cdot 6^{f}$ & 3.41 \\
\hline T3 & 30 & $45 \cdot 4$ & $7 \cdot 56$ & $50 \cdot 5$ & $9 \cdot 21$ & $23 \cdot 9$ & 4.40 \\
\hline T4 & 30 & $50 \cdot 9$ & $6 \cdot 28$ & $53 \cdot 9$ & $6 \cdot 40$ & $20 \cdot 2$ & 2.50 \\
\hline T5 & 30 & $72 \cdot 4^{b}$ & 11.0 & $73 \cdot 2^{d}$ & $11 \cdot 1$ & $32.0^{f}$ & 4.87 \\
\hline T6 & 30 & $47 \cdot 0$ & 6.09 & $54 \cdot 4$ & 7.94 & 22.5 & 2.77 \\
\hline T7 & 30 & $42 \cdot 7$ & $6 \cdot 94$ & $55 \cdot 0$ & $6 \cdot 12$ & $25 \cdot 9$ & $5 \cdot 67$ \\
\hline
\end{tabular}

Peak time and glucose concentration. (T1) white rice; white rice with amino acids (T2) $68 \mathrm{ml}$ at $0 \mathrm{~min}$, (T3) $68 \mathrm{ml}$ at $-15 \mathrm{~min}$, (T4) $68 \mathrm{ml}$ at $-30 \mathrm{~min}$, (T5) $136 \mathrm{ml}$ at $0 \mathrm{~min}$, (T6) $136 \mathrm{ml}$ at $-15 \mathrm{~min}$ and (T7) $136 \mathrm{ml}$ at $-30 \mathrm{~min}$.

a,b,c,d,e,f Mean values within a column with unlike superscript letters were significantly different $(P<0.05)$ potentially reduce blood glucose opens up a new approach to glycaemic control. The major components of EOC are amino acids with a modest amount of carnosine (Table 1). It is also known that serum carnosinase rapidly destroys all ingested carnosine within minutes ${ }^{(40)}$. It is therefore unlikely that carnosine has any significant role in glycaemic control compared with the amino acids present ${ }^{(40)}$.

Gannon, Iverson, Kalogeropoulou \& Nuttall ${ }^{(11,14,15)}$ in a series of papers systematically studied the impact of individual amino acids on glucose solution and reported that the maximum decrease in GR was observed when Ile and Phe were ingested along with a glucose solution ${ }^{(11)}$. In contrast, our study reports for the first time the significant impact of a ready-todrink amino acid mixture in the form of EOC in reducing the GR of rice. On the basis of the above observations, $68 \mathrm{ml}$ of an amino acid mixture was sufficient to reduce GR of high-GI white rice and trigger $\beta$-cell functions especially in the first $30 \mathrm{~min}$. With reference to insulin secretion, it is postulated that the early consumption of an amino acid mixture $15 \mathrm{~min}$ before consumption of rice primes the $\beta$-cell and peripheral tissue for insulin secretion and peripheral tissue for glucose uptake.

To the best of our knowledge, the current study is the first experimental work on humans aimed at using an amino acid mixture to reduce the GR of rice-based diets. It is undeniably an observational study. Its merit lies in enabling people living in Asia to reduce the GR of their carbohydrate-rich rice meals by the inclusion of a ready-to-drink amino acid mixture. The precise mechanism by which these amino acids reduce blood glucose still remains unknown; this will form the next phase of our study.

Diabetes in Asia is the greatest challenge to public health. Any food-based intervention such as that described in this paper should be embraced and encouraged. White rice is an important source of high-GI carbohydrate. It contributes to the dietary glycaemic load leading to hyperglycaemia in Asian populations ${ }^{(27,41,42)}$. Overconsumption of starchy foods such as rice has been reported to induce a rapid and sharp increase in blood glucose $e^{(25,31,43)}$. This increased glucose response is accompanied by an insulin surge and contributes to the aetiology of diabetes $^{(44)}$. As the potency of individual amino acids to influence the glucose response, insulin or glucagon levels varies, it has been a challenge to formulate an amino acid cocktail to optimise its impact on glycaemic reduction ${ }^{(11)}$. Our results indicate that EOC has an amino acid mixture that appears to increase insulin sensitivity and also reduce blood glucose. The novelty of our study is that it provides a simple, practical and reproducible dietary intervention that has significant influence in reducing blood glucose. In view of the fact that most people in Asia enjoy eating rice, the inclusion of the amino acid mixture in the form of EOC may be a useful strategy for reducing the high GI in food in this population.

\section{Acknowledgements}

The authors thank Siow Phei Ching for her technical support.

This research was supported by the Singapore Institute for Clinical Sciences, A*Star, and Cerebos Singapore. 
The authors' contributions are as follows: C. J. H., Y. Y. S. and L. S. contributed to the conception and design of the study. J. L. carried out the study and analysis of blood samples. J. L., Y. Y. S. and L. S. were responsible for the statistical analysis of data. Y. Y. S., J. L. and C. J. H. drafted the manuscript. All authors critically reviewed the contents of the manuscript and approved the final draft.

The authors declare no conflicts of interest.

\section{References}

1. International Diabetes Federation (2014) IDF Diabetes Atlas 2014 Update. Diabetes Atlas. Brussels, Belgium: International Diabetes Federation.

2. Turner RC, Cull CA, Frighi V, et al. (1999) Glycemic control with diet, sulfonylurea, metformin, or insulin in patients with type 2 diabetes mellitus: progressive requirement for multiple therapies (UKPDS 49). JAMA 281, 2005-2012.

3. Pernicova I \& Korbonits M (2014) Metformin - mode of action and clinical implications for diabetes and cancer. Nat Rev Endocrinol 10, 143-156.

4. Gao Y, Yoon KH, Chuang L-M, et al. (2009) Efficacy and safety of exenatide in patients of Asian descent with type 2 diabetes inadequately controlled with metformin or metformin and a sulphonylurea. Diabetes Res Clin Pract 83, 69-76.

5. Umpierrez G, Issa M \& Vlajnic A (2006) Glimepiride versus pioglitazone combination therapy in subjects with type 2 diabetes inadequately controlled on metformin monotherapy: results of a randomized clinical trial. Curr Med Res Opin 22, 751-759

6. Johnston CS, White AM \& Kent SM (2009) Preliminary evidence that regular vinegar ingestion favorably influences hemoglobin A1c values in individuals with type 2 diabetes mellitus. Diabetes Res Clin Prac 84, e15-e17.

7. White AM \& Johnston CS (2007) Vinegar ingestion at bedtime moderates waking glucose concentrations in adults with well-controlled type 2 diabetes. Diabetes Care 30, 2814-2815.

8. Johnston CS, Quagliano S \& White S (2013) Vinegar ingestion at mealtime reduced fasting blood glucose concentrations in healthy adults at risk for type 2 diabetes. J Funct Foods 5 , 2007-2011.

9. Westman E, Yancy W, Mavropoulos J, et al. (2008) The effect of a low-carbohydrate, ketogenic diet versus a low-glycemic index diet on glycemic control in type 2 diabetes mellitus. Nutr Metab 5, 36.

10. Jenkins DA, Kendall CC, McKeown-Eyssen G, et al. (2008) Effect of a low-glycemic index or a high-cereal fiber diet on type 2 diabetes: a randomized trial. JAMA 300, 2742-2753.

11. Gannon MC \& Nuttall FQ (2010) Amino acid ingestion and glucose metabolism - a review. IUBMB Life 62, 660-668.

12. Reilly F, Nolan F \& Lusk G (1898) Phlorhizin diabetes in dogs. Am J Physiol 1, 395-410.

13. Wu H-C \& Shiau C-Y (2002) Proximate composition, free amino acids and peptides contents in commercial chicken and other meat essences. J Food Drug Anal 10, 170-177.

14. Kalogeropoulou D, LaFave L, Schweim K, et al. (2008) Leucine, when ingested with glucose, synergistically stimulates insulin secretion and lowers blood glucose. Metabolism 57, $1747-1752$

15. Nilsson M, Holst JJ \& Björck IME (2007) Metabolic effects of amino acid mixtures and whey protein in healthy subjects: studies using glucose-equivalent drinks. Am J Clin Nutr $\mathbf{8 5}$ 996-1004.
16. van Loon LJC, Saris WHM, Verhagen H, et al. (2000) Plasma insulin responses after ingestion of different amino acid or protein mixtures with carbohydrate. Am J Clin Nutr $\mathbf{7 2}$, 96-105.

17. Iverson JF, Gannon MC \& Nuttall FQ (2013) Ingestion of leucine + phenylalanine with glucose produces an additive effect on serum insulin but less than additive effect on plasma glucose. J Amino Acids 2013, 964637.

18. Nishimura $T$ \& Kato H (1988) Taste of free amino acids and peptides. Food Rev Int 4, 175-194.

19. Nelson G, Chandrashekar J, Hoon MA, et al. (2002) An amino-acid taste receptor. Nature 416, 199-202.

20. Chao JC-J, Tseng H-P, Chang CW, et al. (2004) Chicken extract affects colostrum protein compositions in lactating women. J Nutr Biochem 15, 37-44.

21. Li Y, He R, Tsoi B, et al. (2012) Bioactivities of chicken essence. J Food Sci 77, R105-R110.

22. Sim M-K, Wong Y-C, Xu X-G, et al. (2009) Hypoglycemic action of chicken meat extract in type-2 diabetic KKAy mice and GK rats. Biosci Biotechnol Biochem $\mathbf{7 3}$, 2583-2588

23. Hätönen KA, Virtamo J, Eriksson JG, et al. (2011) Protein and fat modify the glycaemic and insulinaemic responses to a mashed potato-based meal. Br J Nutr 106, 248-253.

24. Gunnerud U, Holst JJ, Ostman E, et al. (2012) The glycemic, insulinemic and plasma amino acid responses to equicarbohydrate milk meals, a pilot-study of bovine and human milk. Nutr J 11, 83.

25. Wolever TM, Jenkins DJ, Jenkins AL, et al. (1991) The glycemic index: methodology and clinical implications. $\mathrm{Am} \mathrm{J}$ Clin Nutr 54, 846-854

26. Sakurai M, Nakamura K, Miura K, et al. (2012) Dietary glycemic index and risk of type 2 diabetes mellitus in middle-aged Japanese men. Metabolism 61, 47-55.

27. Villegas R, Liu S, Gao Y-T, et al. (2007) Prospective study of dietary carbohydrates, glycemic index, glycemic load, and incidence of type 2 diabetes mellitus in middle-aged Chinese women. Arch Inter Med 167, 2310-2316.

28. Sharma RD (1986) Effect of fenugreek seeds and leaves on blood glucose and serum insulin responses in human subjects. Nutr Res 6, 1353-1364.

29. Wolever TM, Jenkins DJ, Ocana AM, et al. (1988) Second-meal effect: low-glycemic-index foods eaten at dinner improve subsequent breakfast glycemic response. AmJ Clin Nutr $\mathbf{4 8}$, 1041-1047.

30. Baecke J, Burema J \& Frijters J (1982) A short questionnaire for the measurement of habitual physical activity in epidemiological studies. Am J Clin Nutr 36, 936-942.

31. Brouns F, Bjorck I, Frayn K, et al. (2005) Glycaemic index methodology. Nutr Res Rev 18, 145-171.

32. Hurwitz BE, Schneiderman N, Marks JB, et al. (2015) Adaptation of $\beta$-cell and endothelial function to carbohydrate loading: influence of insulin resistance. Diabetes 64, 2550-2559.

33. Guzel S, Seven A, Guzel EC, et al. (2013) Visfatin, leptin, and TNF- $\alpha$ : interrelated adipokines in insulin-resistant clinical and subclinical hypothyroidism. Endocr Res 38, 184-194.

34. Wolever TMS, Chiasson J-L, Hunt JA, et al. (1998) Similarity of relative glycaemic but not relative insulinaemic responses in normal, IGT and diabetic subjects. Nutr Res $\mathbf{1 8}$, $1667-1676$.

35. Hanson RL, Pratley RE, Bogardus C, et al. (2000) Evaluation of simple indices of insulin sensitivity and insulin secretion for use in epidemioiogic studies. Am J Epidemiol 151, 190-198.

36. Gerich JE (2003) Clinical significance, pathogenesis, and management of postprandial hyperglycemia. Arch Int Med 163, 1306-1316. 
37. Tura A, Kautzky-Willer A \& Pacini G (2006) Insulinogenic indices from insulin and C-peptide: comparison of beta-cell function from OGTT and IVGTT. Diabetes Res Clin Pract $\mathbf{7 2}$, 298-301.

38. Kalbag JB, Walter YH, Nedelman JR, et al. (2001) Mealtime glucose regulation with nateglinide in healthy volunteers: comparison with repaglinide and placebo. Diabetes Care 24, 73-77.

39. Kim MK, Suk JH, Kwon MJ, et al. (2011) Nateglinide and acarbose for postprandial glucose control after optimizing fasting glucose with insulin glargine in patients with type 2 diabetes. Diabetes Res Clin Pract $92,322-328$.

40. Gardner M, Illingworth KM, Kelleher J, et al. (1991) Intestinal absorption of the intact peptide carnosine in man, and comparison with intestinal permeability to lactulose. J Physiol 439, 411-422.
41. Nanri A, Mizoue T, Noda M, et al. (2010) Rice intake and type 2 diabetes in Japanese men and women: the Japan Public Health Center-Based Prospective Study. Am J Clin Nutr 92, $1468-1477$.

42. Mohan V, Radhika G, Sathya RM, et al. (2009) Dietary carbohydrates, glycaemic load, food groups and newly detected type 2 diabetes among urban Asian Indian population in Chennai, India (Chennai Urban Rural Epidemiology Study 59). Br J Nutr 102, 1498-1506.

43. Ceriello A, Esposito K, Piconi L, et al. (2008) Oscillating glucose is more deleterious to endothelial function and oxidative stress than mean glucose in normal and type 2 diabetic patients. Diabetes 57, 1349-1354.

44. Ludwig DS (2002) The glycemic index: physiological mechanisms relating to obesity, diabetes, and cardiovascular disease. JAMA 287, 2414-2423. 